\title{
Tensile Properties and Deformation Behavior of Several Cast Ni-Based Superalloys Fabricated by Different Solidification Ways
}

\author{
Hai-Tao Li ${ }^{1,2}$ - Yong-Chun Liang ${ }^{3}$ Wan-Li Zhong ${ }^{3}$ Xue-Zhi Qin ${ }^{4}$. \\ Jian-Ting Guo ${ }^{4} \cdot$ Lan-Zhang Zhou ${ }^{4} \cdot$ Wei-Li Ren ${ }^{5}$
}

Received: 29 March 2016/Revised: 21 June 2016/Published online: 11 October 2016

(C) The Chinese Society for Metals and Springer-Verlag Berlin Heidelberg 2016

\begin{abstract}
The tensile properties and deformation behavior of several cast Ni-based superalloys, respectively, in the equiaxed, columnar-crystal and single-crystal styles are comparatively studied. The effects of solidification way, heat treatment and strain rate on the tensile properties are discussed in detail. It is found that the reduction of grain boundaries by the feasible solidification ways offers cast Ni-based superalloys the potential capability of improving the mechanical properties, the ultimate achievement of which is also confirmed to lie on the appropriate modifications of chemical composition and heat treatment. The prolongation of solid solution facilitates the precipitation of fine secondary $\gamma^{\prime}$ phase, whereas the extension of high-temperature aging leads to the coarsening of secondary $\gamma^{\prime}$ phase. The combination of these two aspects has a crucial influence on the tensile properties. Under tensile applied stress, the surface grains of DZ-A alloy deform slightly, while the inner grains deform heavily. This deformation inhomogeneity is ascribed to the occurrence of cracks or oblique grains near the surface of specimens and the sliding or decohesion of grain boundaries between the surface and inner grains. Regardless of strain rate, the ILTDM (intermediate-low-temperature ductility minimum) phenomenon always happens in the temperature range from 400 to $600{ }^{\circ} \mathrm{C}$ in all the investigated alloys, the occurrence of which is closely related to the strong strain-hardening behavior in the deformation process. Finally, the interaction of slip bands which are the main deformation mode below $600{ }^{\circ} \mathrm{C}$ is established to be the essential reason for the strain hardening.
\end{abstract}

KEY WORDS: Ni-based superalloy; Tensile property; Intermediate-low-temperature ductility minimum (ILTDM); Solidification way; Strain rate; Deformation inhomogeneity

Available online at http://link.springer.com/journal/40195

Xue-Zhi Qin

xzqin@imr.ac.cn

$\triangle$ Wei-Li Ren

wlren@staff.shu.edu.cn

1 South China University of Technology, Guangzhou 510641, China

2 Guangdong Power Grid Co. Ltd, Guangzhou 510600, China

3 Electric Power Research Institute of Guangdong Power Grid Corporation, Guangzhou 510080, China

4 Institute of Metal Research, Chinese Academy of Sciences, Shenyang 110016, China

5 Shanghai University, Shanghai 200072, China

\section{Introduction}

Ni-based superalloys have been largely used in the aeronautical and marine applications due to their excellent mechanical, physical and anticorrosion properties [1-4]. As an important aspect of mechanical properties, the tensile performance must be carefully evaluated before superalloys are put to use, which is closely related to the chemical composition, solidification way, heat treatment, strain rate, defects and so on [5]. For example, some researchers considered that when $\mathrm{Ni}$-based cast superalloys were manufactured into the equiaxed, columnar- or singlecrystal forms using different solidification ways, the properties of alloys were significantly improved owing to the decreased amount of grain boundaries [6-8]. 
Strain rate is another key factor which has a complicated effect on the tensile behavior of superalloys. At $700{ }^{\circ} \mathrm{C}$ and below, the ultimate tensile and yield strengths of superalloys were generally insensitive to the strain rate, while at higher temperatures they markedly increased with the increment of strain rate [9-12]. Jensen et al. [13] found that the fracture mode of UDIMET 115 alloy was independent of strain rate; however, Gopinath et al. [14] concluded that heterogeneous deformation occurred by planar slip at all strain rates at low temperatures, whereas homogeneous deformation was present at low strain rates at high temperatures in $720 \mathrm{Li}$ alloy. In addition, it was reported that the tensile fracture modes had a strong dependence on the strain rate in a single-crystal Ni-based superalloy [15].

As superior superalloys with complex compositions are used at higher and higher temperatures, comprehensive and in-depth studies are urgently demanded so that they are better understood and employed in the future. Furthermore, clarifying the roles of various key factors affecting the performance of superalloys and the interaction between them is undoubtedly helpful for their optimal utilization, especially when the operating temperature is increasingly approaching the initial melting temperature of superalloys. Focusing on these aims, the influences of solidification way, strain rate, heat treatment and deformation inhomogeneity on the tensile properties of cast Ni-based superalloys from some novel angle of view were carefully investigated in this work.

\section{Experimental}

Equiaxed K-A, directionally solidified DZ-A and singlecrystal DD-A Ni-based superalloys were, respectively, prepared by conventional cast process and directional solidification ways. The compositions of these alloys were similar, as exhibited in Table 1 . The K-A alloy was subjected to the heat treatment $1120{ }^{\circ} \mathrm{C} / 2 \mathrm{~h} / \mathrm{AC}+850{ }^{\circ} \mathrm{C} /$ $24 \mathrm{~h} / \mathrm{AC}$, while the DZ-A and DD-A alloys were treated by the regime of $1210{ }^{\circ} \mathrm{C} / 2 \mathrm{~h} / \mathrm{AC}+1080{ }^{\circ} \mathrm{C} / 2 \mathrm{~h} /$ $\mathrm{AC}+850{ }^{\circ} \mathrm{C} / 24 \mathrm{~h} / \mathrm{AC}$, which is in fact the standard heat treatment (SHT) of DZ-A alloy. Additionally, a prolonged heat treatment (PHT) of $1210{ }^{\circ} \mathrm{C} / 4 \mathrm{~h} / \mathrm{AC}+1080{ }^{\circ} \mathrm{C} / 4 \mathrm{~h} /$ $\mathrm{AC}+850{ }^{\circ} \mathrm{C} / 24 \mathrm{~h} / \mathrm{AC}$ was conducted on the DZ-A alloy in order to investigate the effect of heat treatment on the tensile properties.

The tensile properties from room temperature (RT) to $1000{ }^{\circ} \mathrm{C}$ were performed on an AG-X $250-\mathrm{kN}$ electric test machine. When the property was tested at $\mathrm{RT}$, the strain rate was always $1.3 \times 10^{-3} \mathrm{~s}^{-1}$, whereas two modes of strain rates, viz. $V_{1}$ or $V_{2}$, were employed at other temperatures. The $V_{1}$ changed from $0.3 \times 10^{-3}$ to $1.7 \times 10^{-3} \mathrm{~s}^{-1}$ at the yielding point, while the $V_{2}$ was constantly $1.3 \times 10^{-3} \mathrm{~s}^{-1}$ during the whole test process. Not less than two specimens were tested at each condition mentioned above.

The microstructures were examined by optical microscopy (OM), scanning electron microscopy (SEM) and transmission electron microscopy (TEM). Chemical etching was used for the general microstructural observation using a solution containing $20 \mathrm{~g} \mathrm{CuSO}_{4}, 50 \mathrm{~mL} \mathrm{HCl}$ and $100 \mathrm{~mL} \mathrm{H}_{2} \mathrm{O}$, which removes $\gamma^{\prime}$ phase.

\section{Results and Discussion}

\subsection{Effect of Solidification Ways on the Tensile Properties}

Figure 1 shows the tensile properties of K-A and DZ-A alloys under the $V_{1}$ mode at different temperatures. It can be seen that the yield strength of the two alloys is very close, but the ultimate tensile strength and elongation of DZ-A alloy are higher than those of K-A alloy. Especially above $800{ }^{\circ} \mathrm{C}$, the elongation of the former is markedly higher than that of the latter.

Figure 2 presents the tensile properties of DZ-A and DD-A alloys under the $V_{2}$ mode. The ultimate tensile and yield strengths of DD-A alloy are lower than those of DZA alloy below $700{ }^{\circ} \mathrm{C}$, whereas they are almost the same above $800{ }^{\circ} \mathrm{C}$. In contrast, the elongation of DD-A alloy is slightly higher than that of DZ-A alloy at all the temperatures.

Indeed, it is unexpected that when the K-A (equiaxed) alloy is upgraded to the DZ-A (columnar) or DD-A (single crystal) alloy using the directional solidification technologies, the tensile properties of alloy are not evidently improved at all, which is very different from the conclusions of the references [6-8].

Table 1 Chemical compositions of the investigated alloys (wt \%)

\begin{tabular}{llllllllllll}
\hline Alloy & C & Cr & Co & W & Mo & Al & Ti & Ta & B & Zr & Ni \\
\hline K-A & 0.09 & 13.9 & 10.0 & 4.3 & 1.5 & 4.0 & 2.7 & 4.7 & 0.03 & 0.03 & Bal. \\
DZ-A & 0.07 & 13.2 & 10.0 & 4.6 & 1.7 & 4.0 & 2.4 & 4.8 & 0.02 & - \\
DD-A & & & & & & & & & & & \\
\hline
\end{tabular}



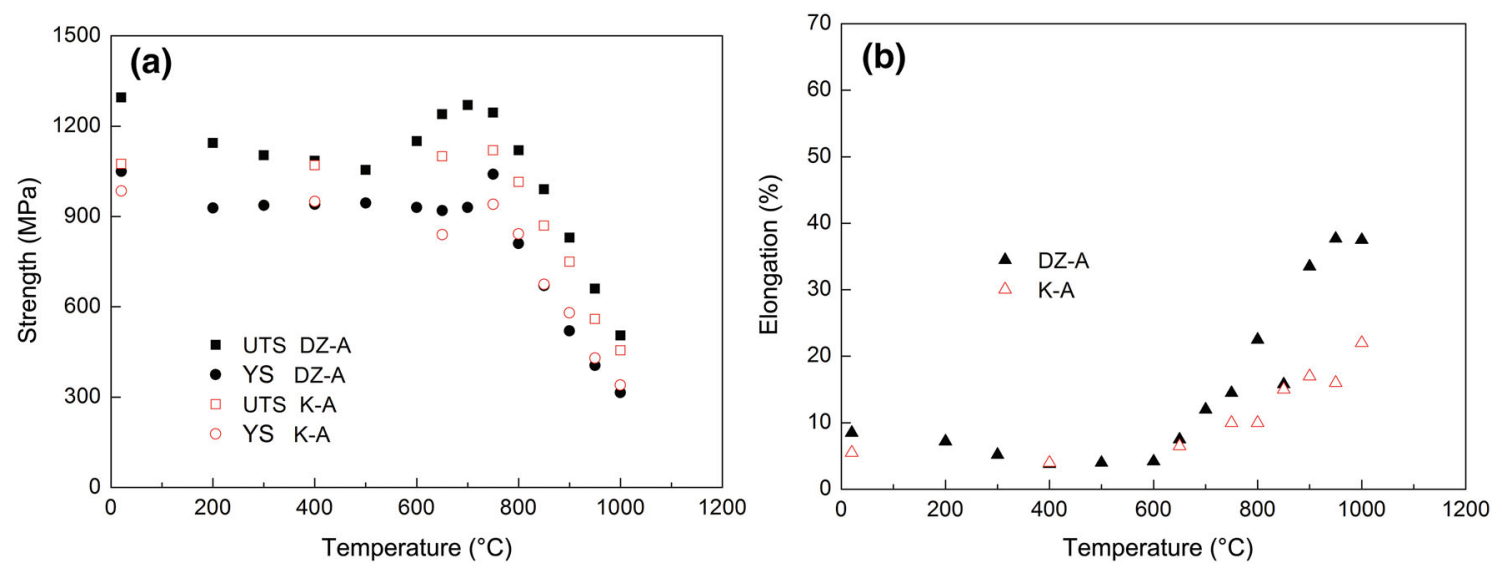

Fig. 1 Strength a and elongation $\mathbf{b}$ variations for K-A and DZ-A alloys under the $V_{1}$ mode at different temperatures
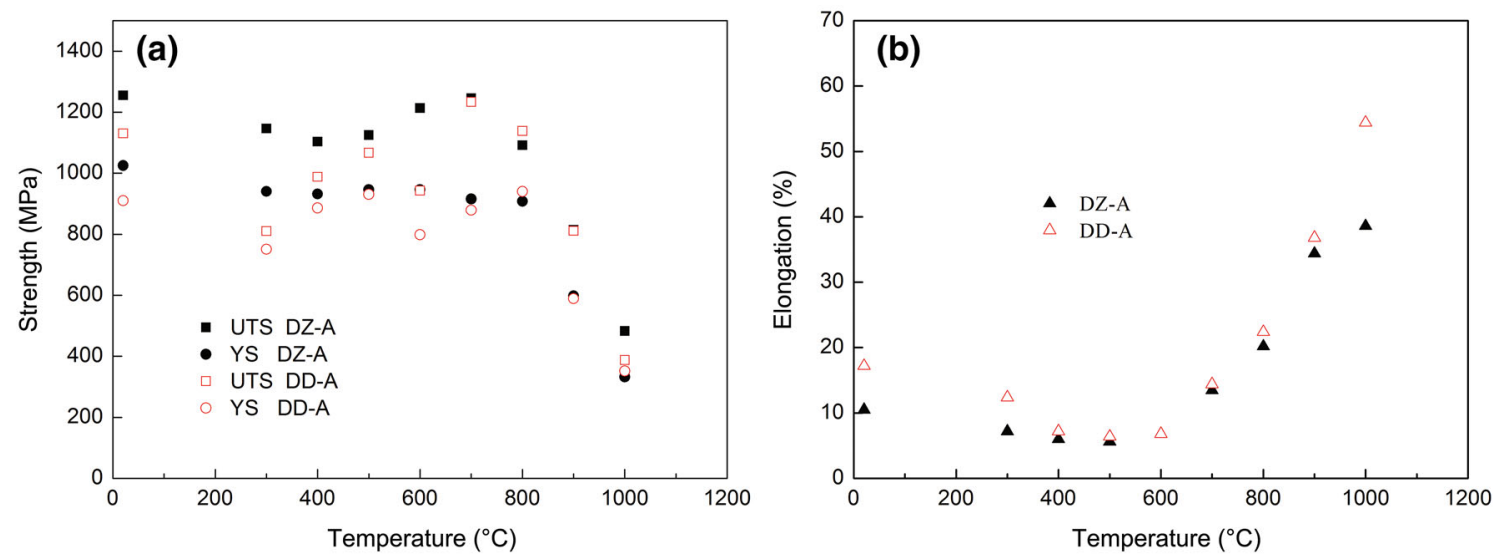

Fig. 2 Strength $\mathbf{a}$ and elongation $\mathbf{b}$ variations for DZ-A and DD-A alloys under the $V_{2}$ mode at different temperatures

In cast Ni-based superalloys, grain boundaries are weak and can be prematurely torn during deformation, especially at elevated temperatures [16-18]. Therefore, the reduction or elimination of grain boundaries by means of appropriate solidification ways is theoretically beneficial for the mechanical properties of alloys. However, the above investigations (Figs. 1,2) indicate that with the reduction of grain boundaries from K-A alloy to DZ-A alloy and to DD-A alloy, the strengths are not always improved, though the elongations increase to some extent. There are probably two reasons responsible for this phenomenon (the DZ-A and DD-A alloys are comparatively studied to disclose the reasons): Firstly, the withdrawing rate of DD-A alloy during solidification was $4 \mathrm{~mm} / \mathrm{min}$, much slower than that of DZ-A alloy $(7 \mathrm{~mm} / \mathrm{min})$, so the dendritic structure was coarser in the DD-A alloy than in the DZ-A alloy (Fig. 3); secondly, when the DZ-A alloy was upgraded to the DD-A alloy by removing all the grain boundaries, the alloying compositions and heat treatment regime of DD-A alloy were not further optimized based on the characteristic of single-crystal alloys, inducing that the alloying and temperature capabilities of DD-A alloy were not adequately displayed in the present investigation.

From the above, it can be concluded that the reduction or elimination of grain boundaries in fact provides cast $\mathrm{Ni}$ based superalloys only a potential capability of improving the mechanical properties, but the improvement has to be ultimately achieved by the appropriate modification and optimization of chemical composition and heat treatment. For example, with the change of cast Ni-based superalloys from common casting to directional solidification and finally to single-crystal style, the additions of grain boundary-strengthening elements such as $\mathrm{C}, \mathrm{B}$ and $\mathrm{Zr}$ should be decreased due to the reduction of grain boundaries; meanwhile, the heat treatment regimes generally become more complicated and the treatment temperatures are higher in order to homogenize the chemical compositions and microstructures of alloys [6, 19, 20].

Regardless of the strain rate modes, the tensile elongations of all the investigated alloys show a trough in the temperature range from 400 to $600{ }^{\circ} \mathrm{C}$ (Figs. 1b, 2b), which is called as intermediate-low-temperature ductility 


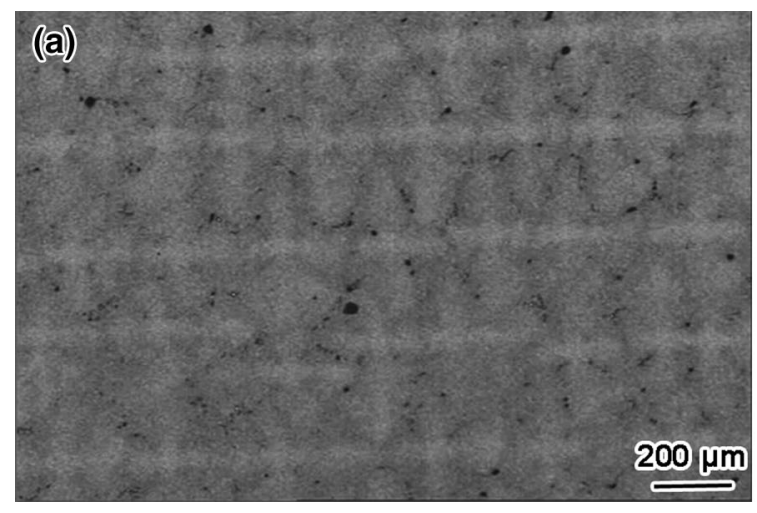

Fig. 3 Dendritic microstructures of DZ-A $\mathbf{a}$ and DD-A $\mathbf{b}$ alloys

minimum (ILTDM) in the present investigation. It is not the ductility minimum that the abnormal yielding strength peak generally corresponds to between 700 and $800{ }^{\circ} \mathrm{C}$ [21] and is neither the so-called intermediate-temperature brittleness (ITB) which occurs due to the oxygen diffusion along the grain boundaries in polycrystalline alloys [22-25]. Indeed, it is a brand-new phenomenon and will be carefully examined elsewhere.

\subsection{Effect of Strain Rate on the Tensile Properties}

The tensile properties of DZ-A alloy under different strain rate modes are summarized in Fig. 4. It can be seen that the yield strength and elongation are as a whole higher at different temperatures under the $V_{2}$ mode than those under the $V_{1}$ mode, whereas the ultimate tensile strength shows a complicated situation: higher below $600{ }^{\circ} \mathrm{C}$ and lower above $700{ }^{\circ} \mathrm{C}$. The strain rate of the $V_{2}$ mode $\left(1.3 \times 10^{-3} \mathrm{~s}^{-1}\right)$ is much larger than that of the $V_{1}$ mode $\left(0.3 \times 10^{-3} \mathrm{~s}^{-1}\right)$ before yielding, which is probably responsible for the higher yield strength and elongation under the $V_{2}$ mode. This conclusion is well supported by the experimental results of Hrutkay et al. [9], which

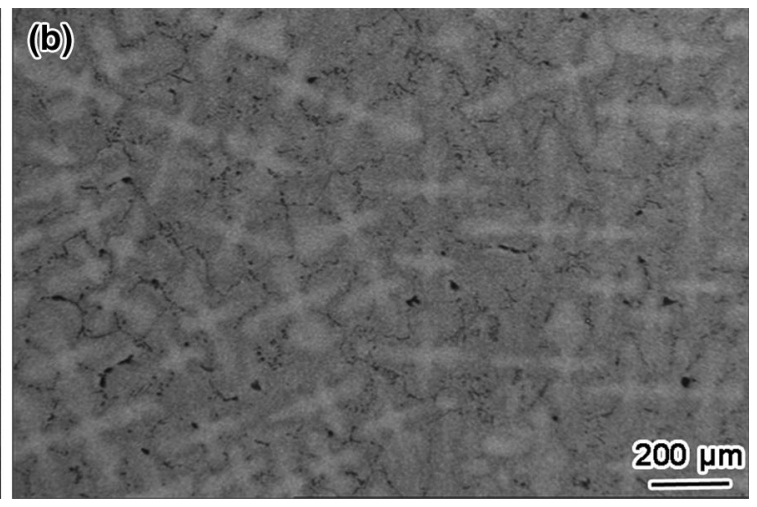

indicated that the strength and elongation of Haynes 230 alloy evidently increased with the increment of strain rate above $700{ }^{\circ} \mathrm{C}$.

The tensile curves of DZ-A alloy under different strain rate modes are shown in Fig. 5. Below $600{ }^{\circ} \mathrm{C}$, the curves mainly include two sections, viz. elastic and strain-hardening stages, while above $700{ }^{\circ} \mathrm{C}$ the curves have three sections, viz. elastic, strain-hardening and strain-softening stages. It seems that the lower elongations at the temperatures lower than $600{ }^{\circ} \mathrm{C}$ can be attributed to the absence of strain softening. In addition, the strain-hardening behavior is so severe from 400 to $600{ }^{\circ} \mathrm{C}$ that the specimens are tensile-ruptured after a very little strain deformation. Comparing Fig. $1 \mathrm{~b}$ and Fig. 2b with Fig. 5, one can find that the severe strain-hardening behavior just occurs at the same temperature as the ILTDM phenomenon mentioned above, suggesting that the former is likely related to the latter.

A terrace is always present on the tensile curves above $900{ }^{\circ} \mathrm{C}$ under the $V_{1}$ mode, and it becomes more remarkable with increasing temperature (Fig. 5a). Careful investigations indicate that the terraces are probably induced by the transition of strain rate from $0.3 \times 10^{-3}$ to

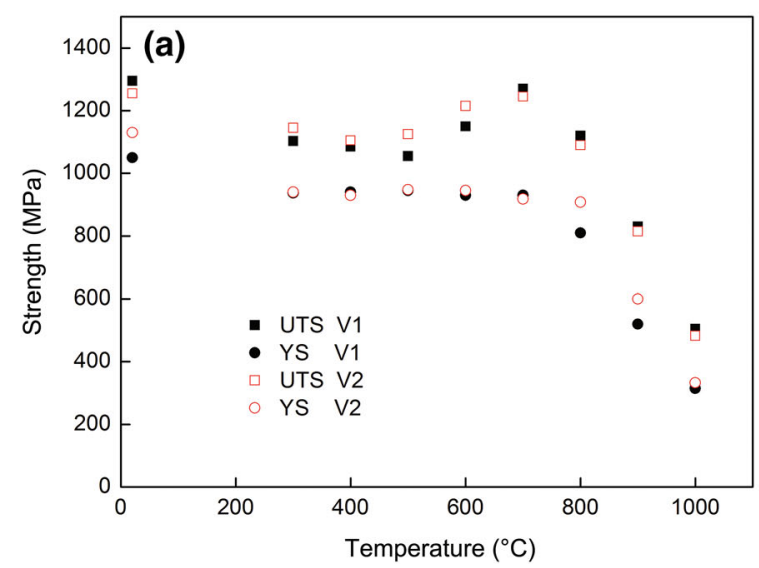

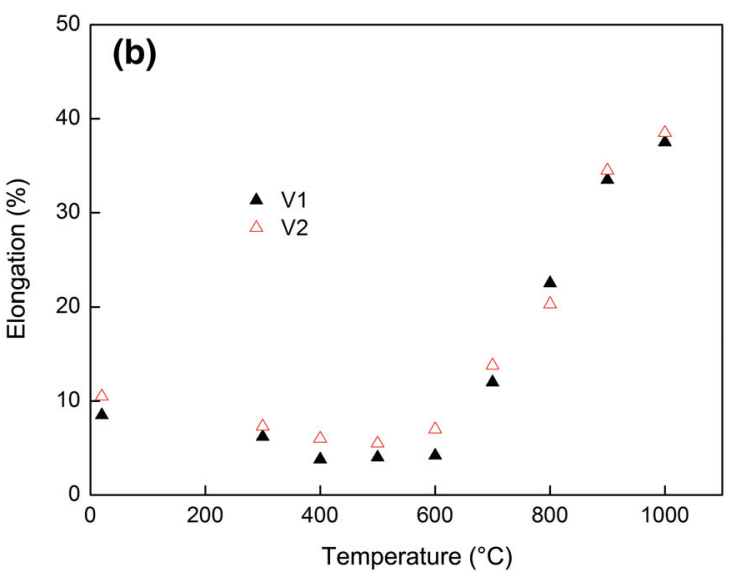

Fig. 4 Strength a and elongation b variations for DZ-A alloys under different strain rate modes at different temperatures 


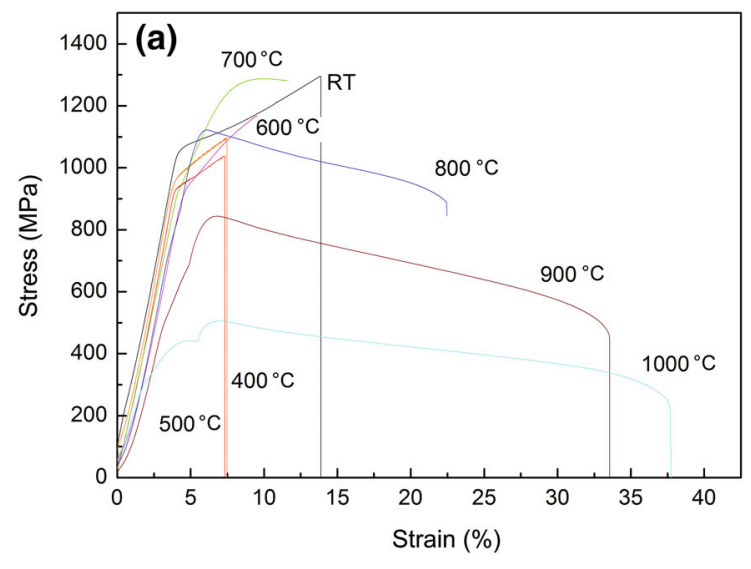

Fig. 5 Stress-strain curves of DZ-A alloys: a $V_{1}$ mode; $\mathbf{b} V_{2}$ mode

$1.7 \times 10^{-3} \mathrm{~s}^{-1}$ at the yielding point under the $V_{1}$ mode because they are not present on the tensile curves of $V_{2}$ mode with a constant strain rate $\left(1.3 \times 10^{-3} \mathrm{~s}^{-1}\right)$ (Fig. 5b). Some researchers previously thought that these terraces resulted from the initiation of new slip systems during deformation, but they did not show the convictive evidences [26-28].

Comparing Fig. 5b with Fig. 6, one can find that the tensile curves of DD-A alloy are very similar to those of DZ-A alloy under the $V_{2}$ mode except that the former shows a slight strain-softening behavior after yielding and before strain hardening below $300{ }^{\circ} \mathrm{C}$, while the DZ-A alloy only displays the elastic and strain-hardening stages on the tensile curves. Tensile curve was reported to well reflect the deformation behavior and mechanism of alloys [29]. Therefore, the DZ-A and DD-A alloys probably experience a similar deformation process based on the alike tensile curves.

The surface slip bands of tensile-ruptured DD-A alloy are carefully observed in order to clarify the deformation behavior and mechanism, as demonstrated in Fig. 7. For

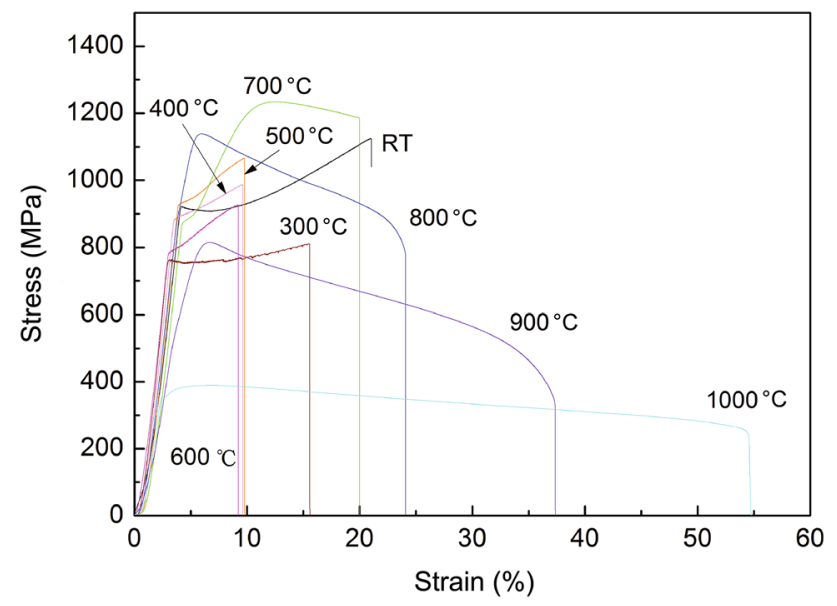

Fig. 6 Stress-strain curves of DD-A alloy under the $V_{2}$ mode

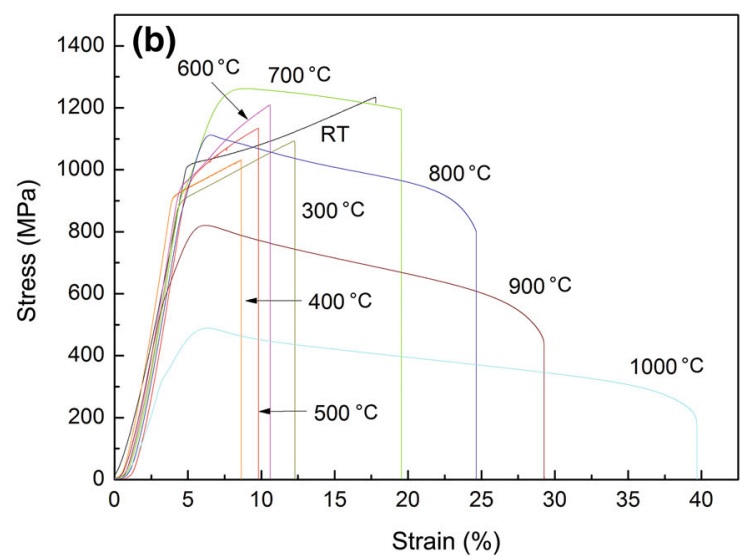

the RT specimen, the primary slip bands are parallel to one another on the surface (Fig. 7a) and occasionally several secondary slip bands can be found in the slip cracks which are in fact the cracked primary slip bands due to the excessive gliding (Fig. 7b), suggesting that the primary slip bands first operate at the early stage of deformation and then the secondary slip bands initiate with increased deformation [30, 31]. When the primary slip bands are not interfered by the secondary slip bands, they freely move, leading to the strain softening of the alloy. As the secondary slip bands proliferate, accumulate and then interact with the primary slip bands, the strain hardening arises and gradually becomes stronger with increasing strain, until the specimen is eventually failed (Fig. 6).

For the specimens in the temperature range from 400 to $600{ }^{\circ} \mathrm{C}$, two primary slip bands in different directions can be always found on the surfaces (Fig. 7c, d). These slip bands probably initiate almost at the same time and often intersect each other, which can undoubtedly result in a stronger strain hardening than the interaction of primary and secondary bands at RT, for the former occurs more frequently and more intensively than the latter. Severe strain hardening damages the deformability of alloys and reduces the ductility [30]. Accordingly, the strain hardening induced by the interaction of slip bands in different directions is likely the essential reason for the presence of the ILTDM phenomena in the present alloys.

Above $700{ }^{\circ} \mathrm{C}$, slip bands become rare or even disappeared with increasing temperature (Fig. 7e, f). Two reasons are mainly responsible for the reduction of slip bands: (i) Oxidation becomes severer and a thick layer of oxidation products covers the surfaces of specimens, making it difficult to observe the slip bands; (ii) more slip systems operate and slip band deformation is gradually substituted by dislocation slip, leading to the reduction of slip bands. The dislocation slip is a more homogeneous deformation mode than the slip band deformation, and accordingly, it 

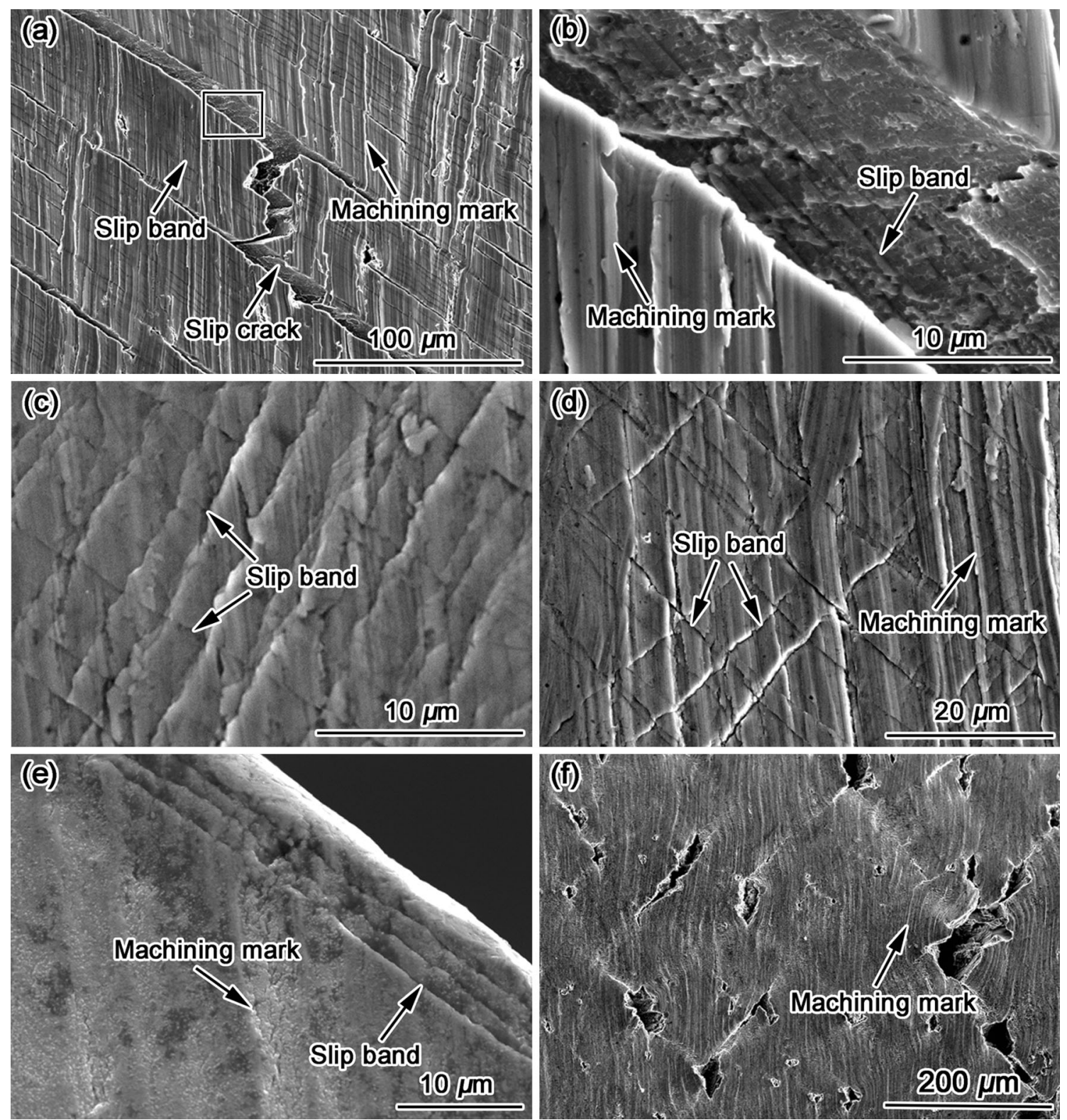

Fig. 7 Surface morphologies of DD-A specimens tensile ruptured at different temperatures: a, b RT; c $400{ }^{\circ} \mathrm{C}$; $\mathbf{d ~} 500{ }^{\circ} \mathrm{C}$; e $700{ }^{\circ} \mathrm{C}$; f $800{ }^{\circ} \mathrm{C}$. b Magnification of the white pane interior in a. Machining mark was produced when the specimens for tensile testing were machined

can evidently enhance the deformability of alloy by replacing the slip band deformation [32,33]. This is why the ductility of the alloy is significantly improved above $700{ }^{\circ} \mathrm{C}$

\subsection{Effect of Heat Treatment on the Tensile Properties}

Table 2 summarizes the tensile properties of DZ-A alloy subjected to different heat treatment regimes. When the regime changes from SHT to PHT, the strengths decrease and the elongations increase at different temperatures, which are different from the research result of Walston et al. [34], who considered that the prolongation of solution time did not change the yield strength, but it enhanced the ultimate tensile strength and elongation. In the present experiments, the elongations are heightened more significantly at the intermediate-low temperature (viz. $500{ }^{\circ} \mathrm{C}$ ) than at the other two temperatures (RT and $900{ }^{\circ} \mathrm{C}$ ), and thus, the ILTDM phenomenon is improved to some degree.

When the solid-solution time is prolonged, more primary $\gamma^{\prime}$ phase and $\gamma / \gamma^{\prime}$ eutectic dissolve into the $\gamma$ matrix, which is beneficial for the precipitation of fine secondary $\gamma^{\prime}$ phase in the period of solid-solution cooling, facilitating the improvement of mechanical properties. The prolongation of high-temperature aging can lead to the coarsening 
Table 2 Tensile properties of DZ-A alloy under different heat treatment conditions

\begin{tabular}{|c|c|c|c|c|c|c|}
\hline \multirow[t]{2}{*}{ Temperature $\left({ }^{\circ} \mathrm{C}\right)$} & \multicolumn{3}{|l|}{ SHT } & \multicolumn{3}{|l|}{ PHT } \\
\hline & UTS (MPa) & YS (MPa) & $\delta(\%)$ & UTS (MPa) & YS (MPa) & $\delta(\%)$ \\
\hline RT & 1255 & 1025 & 10.5 & 1260 & 970 & 11.2 \\
\hline 500 & 1125 & 948 & 5.5 & 1100 & 900 & 8 \\
\hline 900 & 815 & 600 & 34.5 & 795 & 580 & 34.5 \\
\hline
\end{tabular}

of secondary $\gamma^{\prime}$ phase precipitated during the solid-solution cooling, which not only depletes the large quantities of alloying elements from the $\gamma$ matrix, decreasing the strengths, but also broadens the $\gamma$ channels, making dislocation movement easier and accordingly increasing the ductility of the alloy. Though tertiary $\gamma^{\prime}$ phase precipitates during the high-temperature aging cooling, it is not the decisive factor affecting the tensile properties.

\subsection{Inhomogeneous Deformation Behavior of DZ-A Alloy During Tensile Tests}

The morphologies of $\gamma^{\prime}$ phase in the heat-treated and tensile-ruptured DZ-A specimens are compared in Fig. 8. The $\gamma^{\prime}$ phase is cubic in shape, $300 \mathrm{~nm}$ in size and homogeneously distributed along the $<001>$ directions in the $\gamma$ matrix under heat treatment condition (Fig. 8a). The lattice misfit between the $\gamma^{\prime}$ and $\gamma$ phases is about $-0.02 \%$. When the specimens are tensile-ruptured at different temperatures, the $\gamma^{\prime}$ phase tends to directionally align along the applied stress (Fig. 8b-d). The higher the temperature, the more evident the directional alignment. It should be pointed out that the directional alignment here is essentially different from the rafted distribution of $\gamma^{\prime}$ phase vertical to the applied tensile stress in some superalloys with a negative misfit at elevated temperatures [35-37]. The directional diffusion of elements under the applied stress was responsible for the formation of rafted microstructure. However, in the present investigation, it seems that the $\gamma^{\prime}$ phase is forced to directionally move and align along the applied tensile stress during deformation.

The longitudinal microstructures of specimens along the applied stress are shown in Fig. 9. The microstructures in the surface and inner grains of specimens (marked with A
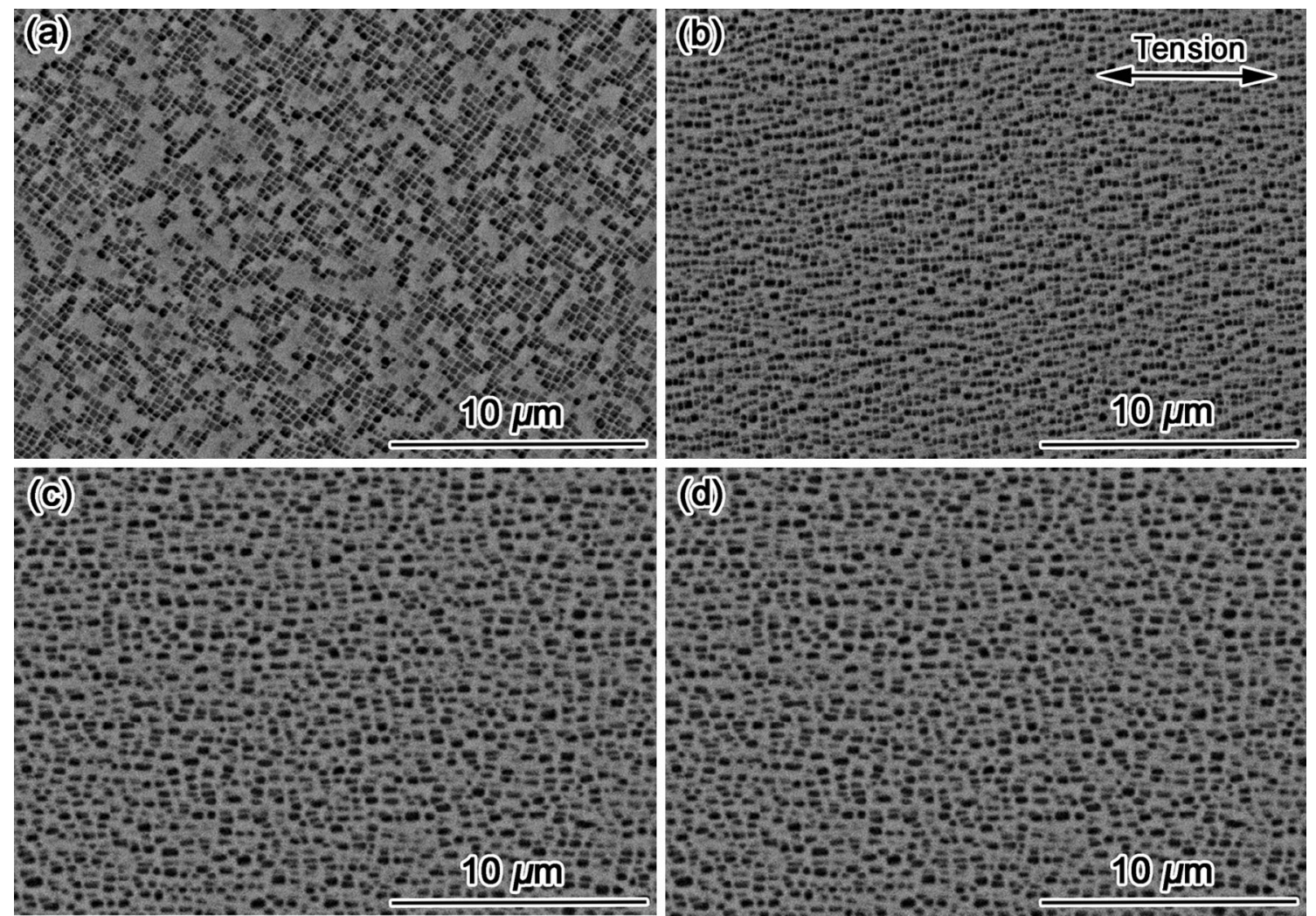

Fig. 8 Distributions of $\gamma^{\prime}$ phase along the applied stress in the heat-treated a and tensile-ruptured DZ-A alloys at $\mathrm{RT} \mathbf{b}, 600{ }^{\circ} \mathrm{C} \mathrm{c}, 900{ }^{\circ} \mathrm{C} \mathrm{d}$ 

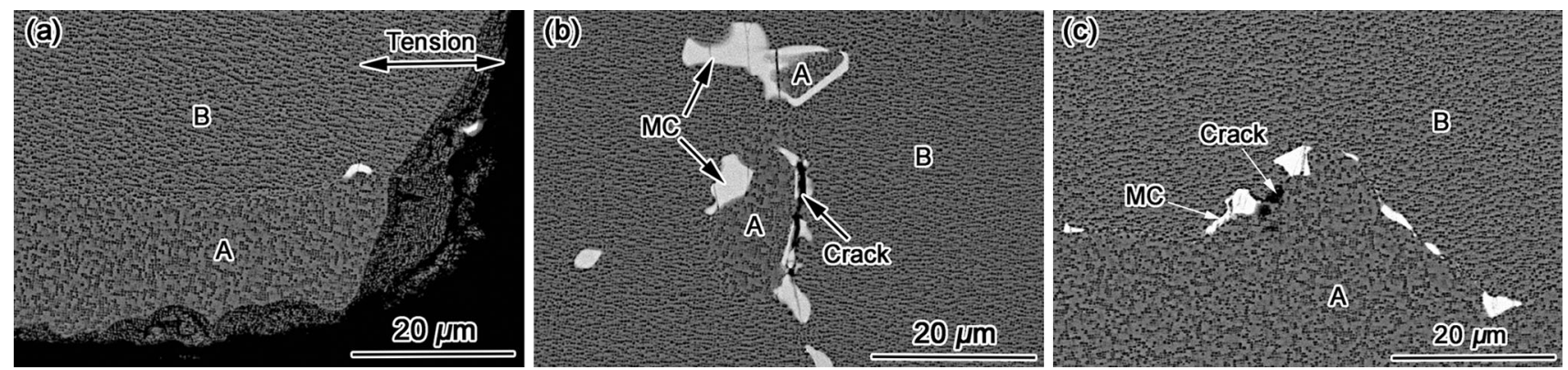

Fig. 9 Longitudinal microstructures of DZ-A alloy tensile ruptured at different temperatures: a, b $700{ }^{\circ} \mathrm{C}$; c $600{ }^{\circ} \mathrm{C}$ (" $A$ " represents the slightly deformed area, and " $B$ " represents the heavily deformed area)
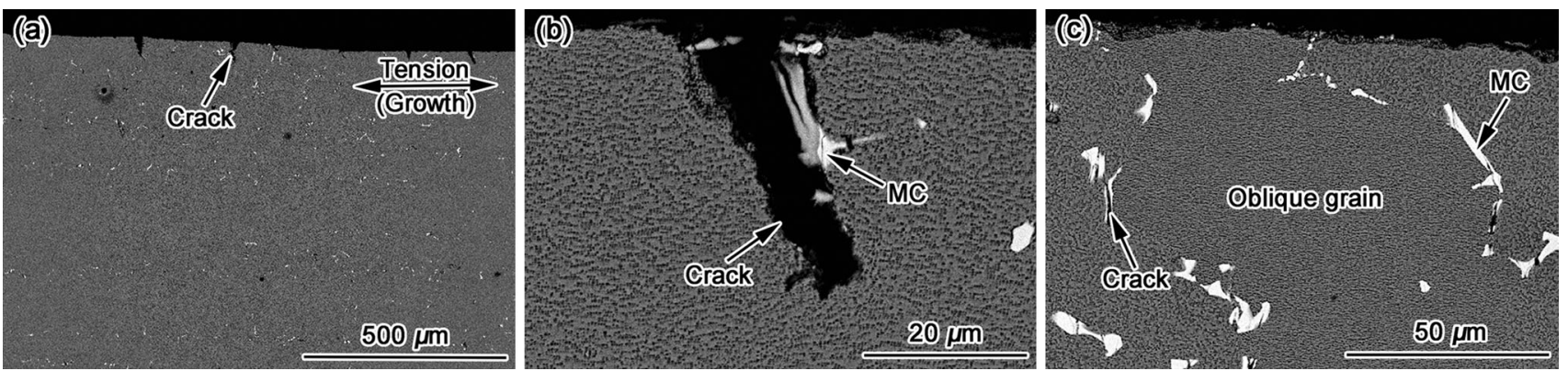

Fig. 10 Surface or near-surface cracks of DZ-A alloy tensile ruptured at $800{ }^{\circ} \mathrm{C}$ : a low-magnification image; $\mathbf{b}$ cracking of carbides; $\mathbf{c}$ cracks on the boundaries between the oblique and regular grains. The bidirectional arrow in a represents the applied stress direction during tension and the growth direction of the DZ-A alloy during solidification

and B in Fig. 9a, c, respectively) are clearly different. The former deforms slightly and the morphology and distribution of $\gamma^{\prime}$ phase are similar to those of $\gamma^{\prime}$ phase under the heat treatment condition, whereas the latter deforms heavily and the $\gamma^{\prime}$ phase tends to directionally distribute along the tensile direction. During deformation, the internal stress between the surface and inner grains can be released through the sliding or decohesion of grain boundaries, or the cracking of MC carbides on the grain boundaries. Therefore, the grain boundaries between the surface and inner grains, like a movable wall, stop the applied stress spreading forth and accordingly lead to the inhomogeneous deformation microstructures. In addition, the $\gamma^{\prime}$ phase enclosed by the skeletal-like MC carbides in the inner grains ("A region" in Fig. 9b) displays the similar characteristic as that of surface grains in Fig. 9a, c, which is probably because that the MC carbides act as a barrier to the applied stress and accordingly protect the $\gamma^{\prime}$ phases from being disturbed by the stress.

The slight deformation of surface grains mentioned above could be ascribed to two reasons: (i) Tearing of carbides or carbide/matrix interfaces near the specimen surface leads to the presence and extension of surface cracks, releasing the stress in the surface grains (Fig. 10a, b); (ii) occurrence of coarse secondary dendritic arms of surface grains or oblique growth of inner grains generates the transverse grain boundaries, which damages the consistency and integrality of surface grains and thus facilitates the presence of cracks vertical to the tension direction (Fig. 10c). These two factors make the surface grains be not basically affected by the applied stress during deformation, so the $\gamma^{\prime}$ phase is almost the same as that under the heat treatment condition.

The deformation inhomogeneity between the surface and inner grains induces that only part of cross section of specimens (that is, the cross section of inner grains) bears the entire applied stress, which is undoubtedly detrimental to the mechanical properties of alloy. Accordingly, during directional solidification the coarse secondary dendritic arms or oblique grains should be avoided as much as possible, and the MC carbides should be controlled to have a blocky shape with a little size.

\section{Conclusions}

1. The reduction or elimination of grain boundaries by the feasible solidification ways provides cast Ni-based alloys the potential capability of improving the mechanical properties, however, its ultimate achievement also depends on the appropriate modifications of chemical composition and heat treatment. 
2. The prolongation of solid-solution time facilitates the precipitation of fine secondary $\gamma^{\prime}$ phase, contributing to the strength of alloy, while the extension of hightemperature aging time can lead to the coarsening of secondary $\gamma^{\prime}$ phase, softening the matrix. The combination of these two aspects eventually induces that the strength of DZ-A alloy decreases and the elongation increases.

3. When tensile deformed along the longitudinal direction, the microstructure of DZ-A alloy presents a significant deformation inhomogeneity, that is, the surface grains deform slightly, while the inner grains undergo a heavy deformation. The occurrence of cracks or oblique grains near the surface of specimens and the sliding or decohesion of grain boundaries between the surface and inner grains are responsible for the deformation inhomogeneity.

4. Regardless of strain rate, the ILTDM phenomenon happens in all the investigated alloys. The absence of strain softening is an important reason for the lower elongation below $600{ }^{\circ} \mathrm{C}$; in addition, strain hardening severely reduces the elongation from 400 to $600{ }^{\circ} \mathrm{C}$, leading to the ILTDM phenomenon. The interaction of slip bands in different directions is determined to be the essential reason for the occurrence of strain hardening.

Acknowledgments This work was supported by the National Natural Science Foundation of China (No. 51001101) and the National Energy Administration Program of China (No. NY20150102).

\section{References}

[1] D.X. Wen, Y. Lin, H.B. Li, X.M. Chen, J. Deng, L.T. Li, Mater. Sci. Eng. A 591, 183 (2014)

[2] J.M. Zhang, Z.Y. Gao, J.Y. Zhuang, Z.Y. Zhong, P. Janschek, J. Mater. Process. Technol. 70, 252 (1997)

[3] B. Du, J. Yang, C. Cui, X. Sun, Mater. Des. 65, 57 (2015)

[4] R.C. Reed, The Superalloys Fundamentals and Applications (Cambridge University Press, New York, 2006), pp. 1-32

[5] Q.Y. Huang, H.K. Li, Superalloys (Metallurgical Industry Press, Beijing, 2000), pp. 9-66 (in Chinese)

[6] J.T. Guo, Materials Science and Engineering for Superalloys (Superalloy Materials and Their Engineering Applications) (Science Press, Beijing, 2010), pp. 543-566 (in Chinese)

[7] R.F. Zhou, Y.F. Han, S.S. Li, High Temperature Structure Materials (National Defence Industry Press, Beijing, 2006), pp. 75-85 (in Chinese)
[8] M.C. Thomas, R.C. Helmink, D.J. Frasier, K. Harris, G.L. Erickson, S.L. Sikkenga, J.M. Eridon, in Proceeding of the 5th Liège Conference, Materials for Advanced Power Engineering 1994, Liège, Belgium, 1994, pp. 1075-1098

[9] K. Hrutkay, D. Kaoumi, Mater. Sci. Eng. A 599, 196 (2014)

[10] L.X. Tian, C.L. Ma, Mater. Sci. Eng. A 620, 198 (2015)

[11] W.W. Milligan, S.D. Antolovich, Metall. Trans. A 18, 85 (1987)

[12] Y.C. Lin, J. Deng, Y.Q. Jiang, D.X. Wen, G. Liu, Mater. Des. 55, 949 (2014)

[13] R.R. Jensen, J.K. Tien, Metall. Trans. A 16, 1049 (1985)

[14] K. Gopinath, A.K. Gogia, S.V. Kamat, R. Balamuralikrishnan, U. Ramamurty, Metall. Trans. A 39, 2340 (2008)

[15] X. Zhang, T. Jin, N.R. Zhao, Z.H. Wang, X.F. Sun, H.R. Guan, Z.Q. Hu, Mater. Sci. Eng. A 492, 364 (2008)

[16] X.Z. Qin, J.T. Guo, C. Yuan, C.L. Chen, H.Q. Ye, Mater. Trans. A 38, 3014 (2007)

[17] A.K. Koul, R. Castillo, Metall. Trans. A 19, 2049 (1988)

[18] E.W. Ross, C.T. Sims, in Superalloys II, ed. by C.T. Sims, N.S. Stoloff, W.C. Hagel (Wiley, New York, 1987), pp. 97-133

[19] X.F. Sun, T. Jin, Y.Z. Zhou, Z.Q. Hu, Mater. China 31, 1 (2012)

[20] Q.Y. Huang, H.K. Li, Superalloys (Metallurgical Industry Press, Beijing, 2000), pp. 140-146. (in Chinese)

[21] Z.K. Chu, J.J. Yu, X.F. Sun, H.R. Guan, Z.Q. Hu, Mater. Sci. Eng. A 527, 3010 (2010)

[22] R.H. Bricknell, D.A. Woodford, Metall. Trans. A 12, 425 (1981)

[23] C.T. Liu, V.K. Sikka, J. Met. 38, 19 (1986)

[24] E.P. George, C.T. Liu, H. Lin, D.P. Hope, Mater. Sci. Eng. A 192/193, 277 (1995)

[25] D.A. Woodford, Metall. Trans. A 12, 299 (1981)

[26] J.L. Liu, Stress Rupture Properties and Microstructural Evolution of a Ni-Base Superalloy. Ph.D. Thesis, Institute of Metal Research, CAS, Shenyang, 2002 (in Chinese)

[27] X. Zhang, Heat Treatment and Tensile, Fatigue Properties of a Ni-Based Single Crystal Superalloy. Ph.D. Thesis, Institute of Metal Research, CAS, Shenyang, 2006 (in Chinese)

[28] Z.K. Chu, Investigation of Mechanical Property and Deformation Mechanism of DZ951 Alloy. Ph.D. Thesis, Institute of Metal Research, CAS, 2008 (in Chinese)

[29] Y.H. Liu, Y.Q. Ning, Z.K. Yao, Y.Z. Li, J.L. Zhang, M.W. Fu, J. Mater. Res. 31, 2164 (2016)

[30] K.V.U. Praveen, G.V.S. Sastry, V. Singh, Metall. Mater. Trans. A 39, 65 (2008)

[31] F. Ebrahimi, J. Yanevich, D.P. Deluca, Acta Mater. 48, 469 (2000)

[32] Z.W. Lian, J.J. Yu, X.F. Sun, H.R. Guan, Z.Q. Hu, Mater. Sci. Eng. A 489, 227 (2008)

[33] I.S. Kim, B.G. Choi, S.M. Seo, D.H. Kim, C.Y. Jo, Mater. Lett. 62, 1110 (2008)

[34] W.S. Walston, I.M. Bernstein, A.W. Thompson, Metall. Trans. A 22, 1443 (1991)

[35] T.M. Pollock, A.S. Argon, Acta Mater. 42, 1859 (1994)

[36] F.R.N. Nabarro, Metall. Trans. A 27, 513 (1996)

[37] O. Paris, M. Fährmann, E. Fährmann, T.M. Pollock, P. Fratzl, Acta Mater. 45, 1085 (1997) 